\title{
International Conference on Social Development and Social Work Education
}

Catholic University of America, Washington, DC Muharram 15-19/July 13-19, 1992

The Twenty-Sixth Congress of the International Association of Schools of Social Work (IASSW) and the Seventh International Conference of the Inter-University Consortium for International Social Development (IUCISD) was held during 13-19 July 1992, in Washington, DC. These biennial international conferences are held simultaneously in the same location to encourage interested social work educators to participate in the activities of both conferences.

IASSW represents the interests of almost two thousand schools of social work and training institutes worldwide. The theme of the 1992 conference was "Realities of Global Interdependence: Challenges to Social Work Education." Papers presented spanned the wide range of interests 
of social work educators, from practice theory formulations to curriculum development to indigenous case materials. They also dealt with many diverse fields of social work practice, for example, from family and child welfare to rural and urban community development. Papers also dealt with clinical practice interests, polity, planning, and social development issues.

IUCISD is a younger multidisciplinary organization of social work educators and other allied professionals with an interest in the broader area of international social development. The theme of the IUCISD 1992 conference was "Strategies of Social Development for Improving the Human Condition." Papers presented covered diverse topics, including social welfare provisions in Eastern Europe and countries of the former Soviet Union, peace and development, sustainable agriculture, refugees, social development skills, social development and indigenous populations, social development and aging populations, social development and children, and many others.

One of the major issues that loomed large throughout the deliberations of the two conferences was the place of values in social work and social development. The treatment of this ideological underpinning and the value base of practice is not new to such conferences. This time, however, the issue managed to come forcefully to the fore, for it cut across most discussions and acquired a certain urgency. There are at least two reasons for the heightened interest in values, despite the traditional attitudes of unquestioning acquiescence: a) The strong multiculturalism movement and the accompanying realization that the white European male and his worldview are no longer the standards against which all people on earth should be measured; and b) The rampant ethnic conflict and strife that the world is witnessing today, as well as the realization that an understanding of ethnicity-let alone constructively dealing with it-is hardly possible in many cases without looking into ideological and religious factors.

Of special significance here is that each conference was preceded by a preconference, a one-day workshop that dealt specifically with these ideological and religious issues. Edward Canda (University of Kansas, Lawrence, KS) organized a precongress institute on "Spirituality and Social World Curriculum." Discussions revolved around what Judaism, Christianity, Islam, Buddhism, and Shamanism have to say about social work theory and practice. All participants agreed that social work can no longer afford to ignore the vital role played by belief systems in the helping relationship if our intervention is to be as effective as we hope.

On the other hand, Thomas Walz (University of Iowa, Iowa City, IA) organized a workshop on "Ghandian Thought as Theory Base for Social Work." Basic Gandhian concepts presented by Walz et al., as relevant for 
helping social work out of its current malaise include, inter alia, a) the basic unity of all things; b) individual self-realization as the core of human existence; c) social responsibility; d) nonviolence and material simplicity; and e) service to the oppressed. The rich discussions of these ideas shows clearly the need for universal guiding principles that should not necessarily be limited to the traditional Western value system.

Many participants in these conferences felt that a gap existed in the area of Islamic concepts relevant to social work theory and practice. Very little has been or is currently being written on the subject in the English language. Particular issues that deserve attention are: a) characterization of God in Islam and its effects on client adjustment; b) guilt and absolution as they affect intra- and interpersonal dynamics; c) relation of the concept of predestination to mental health; d) impact of the belief in the hereafter on the here and now; and e) meaning of the Islamic worldview for individual and societal development.

Ibrahim Rajab

Professor and Chairman, Department of Social Work Imam Muhammad ibn Saud Islamic University Riyadh, Saudi Arabia 